\title{
Basic and applied uses of molecular approaches in freshwater ecology
}

\author{
Jane M. Hughes ${ }^{1,6}$, Debra S. Finn ${ }^{2,7}$, Michael T. Monaghan ${ }^{3,8}$, Alicia Schultheis ${ }^{4,9}$, \\ and Bernard W. Sweeney ${ }^{5,10}$ \\ ${ }^{1}$ Australian Rivers Institute and National Environmental Research Program, Northern Australia Hub, Griffith School of \\ Environment, Griffith University, Nathan, Queensland 4111, Australia \\ ${ }^{2}$ Zoology Department, Oregon State University, Corvallis, Oregon 97331 USA \\ ${ }^{3}$ Leibniz-Institute of Freshwater Ecology and Inland Fisheries (IGB), Müggelseedamm 301, 12587 Berlin, Germany \\ ${ }^{4}$ Biology Department, Stetson University, DeLand, Florida 32723 USA \\ ${ }^{5}$ Stroud Water Research Center, Avondale, Pennsylvania 19311 USA
}

Special sessions focusing on the use of molecular methods in freshwater ecology have been held every few years at the annual meeting of the North American Benthological Society, now the Society for Freshwater Science. The first such session was held in Duluth, Minnesota, in 1999, and was followed by sessions in Pittsburgh, Pennsylvania (2002); Anchorage, Alaska (2006); Grand Rapids, Michigan (2009); and Louisville, Kentucky (2012) (USA). To date, only the participants in the Grand Rapids session contributed a special series to the Society's journal, Journal of the North American Benthological Society (J-NABS, now Freshwater Science [FWS]) (Monaghan et al. 2010). The papers in the current special series in FWS come largely from 2 special sessions at the meeting in Louisville: 'Genetic tools in the study of biodiversity, ecology and evolution of aquatic organisms' and 'Application of molecular taxonomy to bioassessment: bugs to bar-codes-what does it all mean?'

The complexity of methods applied and questions addressed in these sessions has increased over time. Authors in early sessions focused on the use of allozymes, whereas authors in more recent sessions have presented papers based on mitochondrial (mt) deoxyribonucleic acid (DNA) sequence data and microsatellites. The main questions addressed have concerned mechanisms and patterns of dispersal among populations, inferences about past distributions and refugia (phylogeography), and phylogenetics and recognition of cryptic species. Many of the authors of papers in the current special series addressed similar questions, but used more sophisticated molecular or statistical approaches. In addition, more attention was given to com- bining other novel approaches with genetics to answer specific questions. The increasing number of papers, diversity of topics, and complexity of analyses in these special sessions reflects the rapidly increasing availability of specialized molecular tools and conceptual advances in applying these tools in ecology.

DNA barcoding was proposed $>10$ y ago as an efficient method for species identification. Much effort has gone toward testing how well DNA barcodes can identify morphological species. However, whether this additional information will change conclusions about the effects of natural and anthropogenic disturbance on communities remains largely untested. Several authors of papers in this series addressed these important questions.

The first 3 papers in the series focused on contemporary dispersal of stream fauna. Yaegashi et al. (2014) analyzed microsatellite loci in a riverine caddisfly in Japan and used multiple statistical approaches to examine population genetic structure. They incorporated approaches that did not require a priori assignment of individuals to populations and demonstrated unexpected subdivision between upland and lowland populations, which they propose may result from local adaptation. Elbrecht et al. (2014) used a combination of mitochondrial and singlecopy nuclear gene-sequence data and 3 microsatellite loci to investigate dispersal potential in a predatory stonefly. They showed that, despite the presence of 2 distinct groups of mitochondrial haplotypes, populations were mostly connected and interbreeding occurred between the 2 haplotype groups. Schmidt et al. (2014) combined analysis

E-mail addresses: ${ }^{6}$ jane.hughes@griffith.edu.au; ${ }^{7}$ finnd@science.oregonstate.edu; ${ }^{8}$ monaghan@igb-berlin.de; ${ }^{9}$ aschulth@stetson.edu;
${ }^{10}$ sweeney@stroudcenter.org

DOI: 10.1086/675254. Received 18 November 2013; Accepted 19 November 2013; Published online 22 January 2014.

Freshwater Science. 2014. 33(1):168-171. () 2014 by The Society for Freshwater Science. 
of otolith microchemistry with mitochondrial DNA sequence data and microsatellite loci to examine the behavior of 2 fish species thought to exhibit different forms of diadromy. They used the otolith information to identify which parts of an individual's life history were spent in freshwater vs marine conditions and genetic data to infer the extent of dispersal among river systems.

Finn et al. (2014) examined probable effects of the loss of alpine glaciers on genetic diversity in a baetid mayfly. They used sequence data from the mitochondrial cytochrome $c$ oxidase subunit I (COI) gene and compared populations in recently deglaciated mountain ranges with those in the still-glaciated Pyrenees mountain range. Their results strongly suggested that the regional habitat heterogeneity created by the unique hydrological effects of glaciers promotes genetic diversity in glaciated regions. They concluded that the predicted disappearance of small alpine glaciers within decades will result in substantial loss of genetic diversity in these mayflies.

Analysis of DNA sequence data can give valuable information about the history of populations and allows inference of the processes that may have led to their current distributions (Avise 2000). Based on molecular-clock models, DNA-sequence data can be used to infer the time at which populations became isolated from one another. Hurwood et al. (2014) used mtDNA sequences and microsatellites to examine the genetic structure of the giant freshwater prawn across its entire range from western India to western Java. This very broad distribution is unusual for a purely freshwater species that lacks the ability to fly or tolerate high salinities. The molecular data suggested that in some parts of the range, gene flow among populations occurred during times of low sea levels when rivers that are currently isolated from one another potentially were connected. Hurwood et al. (2014) proposed that freshwater plumes during flooding connected populations in other parts of the range. Pessino et al. (2014) used sequence data from the COI gene to infer the past history of a widespread stonefly in eastern North America. They used molecular-clock calculations to infer the locations of Pleistocene refugia and of possible barriers to dispersal in the species.

Comparative phylogeography involves the analysis of multiple species from the same region. The general idea is that if multiple species show the same patterns across a region, or e.g., between 2 drainages, the patterns are likely to have been caused by the same historical event. Previšić et al. (2014) combined molecular data from the COI gene with species-distribution modeling to infer the histories of 3 endemic and 1 widespread caddisfly species in the karst areas of the Western Balkan Peninsula. The molecular data showed deep divergence among populations of the 3 endemic species, and much lower levels of divergence among the widespread species. Based on combined findings from the species-distribution models and genetic data, the authors suggested that the endemic species had persisted and diversified in their current locations during past climate oscillations.

Authors of the next 2 papers compared multiple species of freshwater fish across northern Australia. Cook et al. (2014) concentrated on 3 species with similarly disjunct distributions across central northern and northeastern Australia. Like many other authors in this series, they used COI gene sequences to infer the history of the 3 species. Despite similarity in present-day distributions, the 3 species differed in overall diversity, the number of distinct lineages within each species, and the spatial distribution of lineages. Huey et al. (2014) examined 5 species from the same region but with broader distribution patterns. Again, phylogeographic patterns differed among species. Some species were highly structured and others showed no obvious divergence across the entire region. Both studies revealed 2 consistent patterns. First, all species sampled from around the Gulf of Carpentaria showed evidence of historical connections among rivers during the mid- to late-Pleistocene, consistent with the hypothesis that the region contained a large freshwater lake that connected the various drainages. Second, all species that occurred on the eastern and western of Cape York Peninsula showed evidence of historical connection, consistent with some form of historical river rearrangement in the area.

This special series highlights the growing use of molecular data in both basic and applied aspects of freshwater research. Freshwater scientists have embraced the idea that DNA-barcoding approaches may be particularly useful for analyzing community structure when morphology may not be a good indicator of species status and where sufficiently trained taxonomists are rare. When the DNAbarcoding approach is combined with next generation sequencing (NGS), the quantity of data available is enormous. Five authors in this series used DNA barcoding.

Three authors addressed the significance of additional sensitivity provided by species identification using DNA barcoding. Gill et al. (2014) assessed trends in species diversity patterns along elevation gradients. They focused on Ephemeroptera, Plecoptera, Trichoptera (EPT) taxa in 3 watersheds in the Colorado Rocky Mountains and compared the results from morphological species identification with those from DNA barcodes. DNA barcoding identified more species than did morphology, but the barcoding approach showed a significantly negative trend in $\beta$ diversity with elevation, whereas the morphological approach did not, a result suggesting that the molecular approach may identify subtle differences not detectable with moreconventional techniques. Stein et al. (2014) also compared results from morphology- and barcode-based species identification. They used both approaches to compare bioassessment metrics between disturbed and undisturbed sites in 2 streams. They found no differences between disturbed and undisturbed sites with metrics based on spec- 
imens identified morphologically to the family/genus/ species level but significant differences in $50 \%$ of comparisons with metrics based on specimens identified to species level by barcoding. Jackson et al. (2014) addressed the loss of species diversity as a result of human disturbance that would be identified when using the 2 methods. They examined an enormous number of specimens morphologically (5870) and barcoded 91\% of these specimens. Their results suggest that macroinvertebrate biodiversity in streams and the loss of that biodiversity caused by environmental degradation has been substantially underestimated in the past. Thus, all of these authors identified a stronger effect with barcode-based data/metrics than with morphologybased data/metrics.

Identification of immature forms of relatively unknown aquatic insect groups to species often is not possible because most of the taxonomy is based on adults. AvelinoCapistrano et al. (2014) used the DNA-barcoding approach to associate adult and immature stages of a genus of stonefly. Future investigators will be able to identify the immature forms of a number of species based on the descriptions by Avelino-Capistrano et al. (2014), who described the male genitalia of another species for the first time.

The DNA-barcoding approach has been used for $>10 \mathrm{y}$, but how species should be delimited with this approach is still under discussion. White et al. (2014) used DNAbarcode data from 3 genera and $>2000$ sequences and compared number of species detected with several combinations of tree-reconstruction methods and species-delimitation criteria. Neighbor-joining trees combined with a $2 \%$ cutoff yielded the greatest number of species.

Authors of the final papers in the series described relatively new molecular techniques. Kermarrec et al. (2014) used NGS to analyze diatom communities from environmental samples. The lack of taxonomic coverage in DNA reference libraries resulted in detection of more species by microscopy than by NGS. However, pyrosequencing is a promising approach for detecting all diatom species, even rare ones, once reference libraries are better developed.

Almost all of the phylogeographic studies in this series were based solely on mtDNA or a combination of mtDNA and microsatellites. Microsatellites are useful for addressing questions about, e.g., dispersal and paternity, but they are not as useful for phylogeographic studies because the mutation models are not clear. Also, microsatellite loci tend to be species-specific, so the same loci often cannot be used in comparative phylogeographic studies. Therefore, a combination of mitochondrial and nuclear sequence data should be used when possible (Brito and Edwards 2009). Schultheis et al. (2014) explored the utility of NGS-based transcriptome sequencing for identifying anonymous nuclear loci useful for addressing intraspecific questions in freshwater ecology. They produced transcriptomes for the stonefly, Hesperoperla pacifica, and used them to isolate thousands of potentially useful nuclear loci. They demon- strated proof-of-concept by screening 40 polymerase chain reaction (PCR) primer pairs across 4 populations for their ability to detect genetic variation. These primers yielded 5 loci that were used to produce nuclear DNA sequences for analysis in population genetic and phylogeographic analyses of this species. Thousands more loci remain to be screened, and the primers have the potential to be applied to other species. Use of multiple genes holds great promise for improving the resolution of population genetic and phylogeographic studies (Brito and Edwards 2009).

In summary, this series covers a range of ecological questions to which molecular approaches have been applied. The topics range from populations and contemporary dispersal to phylogeography, the use of DNA barcodes, and some new methods. For population analysis, the use of multiple genetic markers and combinations of molecular techniques with other new approaches, such as otolith microchemistry and species-distribution modeling have added to the weight of conclusions. The phylogeographic studies highlight the different effects of Pleistocene climate change on aquatic fauna in temperate and tropical regions. In temperate regions, glaciation caused loss of habitat and forced species to retreat to warmer refugia, whereas in more-tropical regions, sea-level change had the greatest effect by directly connecting and disconnecting river systems and the fauna they contain. The barcoding studies demonstrate the more-precise species identification offered by this approach, although questions still remain about criteria for species delimitation. Nevertheless, the approach appears to offer potential for identifying subtle effects of disturbance on aquatic communities. Last, modern technology is opening many new opportunities for molecular ecologists. Perhaps the next molecular special series will consist only of studies based on NGS.

\section{LITERATURE CITED}

Avelino-Capistrano, F., J. L. Nessimian, J. R. Santos-Mallet, and D. M. Takiya. 2014. DNA-based identification and descriptions of immatures of Kempnyia Klapálek (Insecta:Plecoptera) from Macaé River Basin, Rio de Janeiro State, Brazil. Freshwater Science 33:325-337.

Avise, J. C. 2000. Phylogeography: the history and formation of species. Harvard University Press, Cambridge, Massachusetts.

Brito, P. H., and S. V. Edwards. 2009. Multilocus phylogeography and phylogenetics using sequence-based markers. Genetica 135:439-455.

Cook, B. D., P. J. Unmack, J. A. Huey, and J. M. Hughes. 2014. Do common disjunct populations of freshwater fishes in northern Australia form from the same biogeographic events? Freshwater Science 33:263-272.

Elbrecht, V., C. K. Feld, M. Gies, D. Hering, M. Sondermann, R. Tollrian, and F. Leese. 2014. Genetic diversity and dispersal potential of the stonefly Dinocras cephalotes in a central European low mountain range. Freshwater Science 33:181-192.

Finn, D. S., C. Zamora-Muñoz, C. Múrria, M. Sáinz-Bariáin, and J. Alba-Tercedor. 2014. Evidence from recently deglaci- 
ated mountain ranges that Baetis alpinus (Ephemeroptera) could lose significant genetic diversity as alpine glaciers disappear. Freshwater Science 33:207-216.

Gill, B. A., R. A. Harrington, B. C. Kondratieff, K. R. Zamudio, N. L. Poff, and W. C. Funk. 2014. Morphological taxonomy, DNA barcoding, and species diversity in southern Rocky Mountain headwater streams. Freshwater Science 33:288-301.

Huey, J. A., B. D. Cook, P. J. Unmack, and J. M. Hughes. 2014. Broadscale phylogeographic structure of five freshwater fishes across the Australian Monsoonal Tropics. Freshwater Science 33:273-287.

Hurwood, D. A., S. Dammannagoda, M. N. Krosch, H. Jung, K. R. Salin, M. A.-B. H. Youssef, M. de Bruyn, and P. B. Mather. 2014. Impacts of climatic factors on evolution of molecular diversity and the natural distribution of wild stocks of the giant freshwater prawn (Macrobrachium rosenbergii). Freshwater Science 33:217-231.

Jackson, J. K., J. M. Battle, B. P. White, E. M. Pilgrim, E. D. Stein, P. E. Miller, and B. W. Sweeney. 2014. Cryptic biodiversity in streams: a comparison of macroinvertebrate communities based on morphological and DNA barcode identifications. Freshwater Science 33:312-324.

Kermarrec, L., A. Franc, F. Rimet, P. Chaumeil, J.-M. Frigerio, J.-F. Humbert, and A. Bouchez. 2014. A next-generation sequencing approach to river biomonitoring using benthic diatoms. Freshwater Science 33:349-363.

Monaghan, M. T., S. U. Pauls, J. M. Hughes, and C. T. Robinson. 2010. Evolutionary ecology, systematics, speciation, and phylogeography in benthology-Preface. Journal of the North American Benthological Society 29:1024-1036.
Pessino, M., E. T. Chabot, R. Giordano, and R. E. DeWalt. 2014. Refugia and postglacial expansion of Acroneuria frisoni Stark \& Brown (Plecoptera:Perlidae) in North America. Freshwater Science 33:232-249.

Previšić, A., J. Schnitzler, M. Kučinić, W. Graf, H. Ibrahimi, M. Kerovec, and S. U. Pauls. 2014. Microscale vicariance and diversification of Western Balkan caddisflies linked to karstification. Freshwater Science 33:250-262.

Schmidt, D. J., D. A. Crook, J. I. Macdonald, J. A. Huey, B. P. Zampatti, S. Chilcott, T. A. Raadik, and J. M. Hughes. 2014. Migration history and stock structure of two putatively diadromous teleost fishes, as determined by genetic and otolith chemistry analyses. Freshwater Science 33:193-206.

Schultheis, A. S., N. Davis, J. T. Page, A. M. Fenwick, J. E. Bond, and D. K. Shiozawa. 2014. Comparative transcriptomics allows for rapid development of population-level nuclear markers in Hesperoperla pacifica (Plecoptera:Perlidae). Freshwater Science 33:364-373.

Stein, E. D., B. P. White, R. D. Mazor, J. K. Jackson, J. M. Battle, P. E. Miller, E. M. Pilgrim, and B. W. Sweeney. 2014. Does DNA barcoding improve performance of traditional stream bioassessment metrics? Freshwater Science 33:302-311.

White, B. P., E. M. Pilgrim, L. M. Boykin, E. D. Stein, and R. D. Mazor. 2014. Comparing four species-delimitation methods applied to a DNA barcode data set of insect larvae for use in routine bioassessment. Freshwater Science 33:338-348.

Yaegashi, S., K. Watanabe, M. T. Monaghan, and T. Omura. 2014. Fine-scale dispersal in a stream caddisfly inferred from spatial autocorrelation of microsatellite markers. Freshwater Science 33:172-180. 